\title{
Na ausência de endereço, onde mora a saúde? Determinantes sociais e populações de ocupações
}

\author{
In the absence of an address, where does health live? Social \\ determinants and occupation populations

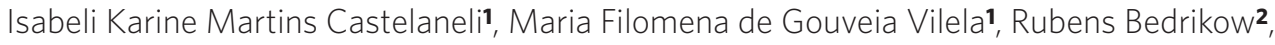 \\ Débora de Souza Santos' ${ }^{1}$ Maura Cristiane e Silva Figueira'
}

DOI: $10.1590 / 0103-110420195801$

RESUMO Pesquisa qualitativa cujo objetivo foi analisar a influência dos Determinantes Sociais da Saúde no processo saúde-doença de população residente em área de ocupação de Campinas, com enfoque no acesso aos serviços de saúde, habitação (condições de moradia, água e esgoto) e trabalho (emprego e renda). Utilizaram-se entrevistas semiestruturadas com moradores e dados secundários oriundos de censo comunitário elaborado por lideranças locais para traçar o perfil sociodemográfico da população em estudo. Os resultados encontrados indicam desigualdades regionais reveladas nessa ocupação, onde a condição de pobreza, a miséria, a violência, o desemprego e a falta de acesso a direitos básicos de cidadania determinam a piora das condições de saúde de seus moradores. Conhecer e compreender como Determinantes Sociais da Saúde atuam no processo saúde-doença da população pode contribuir para que governos, profissionais de saúde e outros atores sociais, incluindo universidades públicas, intervenham, principalmente, com políticas públicas que busquem reduzir o impacto desses fatores e promover a melhoria das condições de vida e saúde dessas populações, vivendo na invisibilidade social, sujeitas a preconceitos e discriminação de diversas naturezas por parte da sociedade.

PALAVRAS-CHAVE Determinantes Sociais da Saúde. Processo saúde-doença. Saúde pública. Território ocupado. Estratégia Saúde da Família.

1 Universidade Estadual de Campinas (Unicamp), Faculdade de Enfermagem - Campinas (SP), Brasil. isakm.cast@gmail.com

2 Universidade Estadual de Campinas (Unicamp), Faculdade de Ciências Médicas - Campinas (SP), Brasil.

ABSTRACT Qualitative research in which the objective was to analyze the influence of the Social Determinants of Health on the health-disease process of the population living in the urban slum/occupation area of Campinas, focusing on access to health services, housing (housing, water, and sewage conditions) and work (employment and income). Semi-structured interviews with residents and secondary data from a community census prepared by local leaders were used to trace the sociodemographic profile of the population under study. The results found indicate regional inequalities revealed in the occupation, where the condition of poverty, misery, violence, unemployment, and lack of access to basic citizenship rights determine the worsening of the health conditions of its residents. Knowing and understanding how Social Determinants of Health work in the health-disease process of the population can contribute so that governments, health professionals, and other social actors, including public universities, can intervene, mainly with public policies that seek to reduce the impact of these factors and promote the improvement of living conditions and health of these populations, living in social invisibility, subject to prejudice and discrimination of various kinds by society in general.

KEYWORDS Social Determinants of Health. Health-disease process. Public health. Occupied territory. Family Health Strategy. 


\section{Introdução}

A pesquisa teve como objetivo analisar como os Determinantes Sociais da Saúde (DSS) influenciam o processo saúde-doença de populações em contexto de alta vulnerabilidade social (ocupações), com ênfase no acesso aos serviços de saúde, moradia e trabalho, bem como identificar a compreensão dessa população sobre a relação dos DSS com o seu adoecimento.

O conceito de DSS utilizado no estudo é:

Para a Comissão Nacional sobre os Determinantes Sociais da Saúde (CNDSS), os DSS são os fatores sociais, econômicos, culturais, étnicos/raciais, psicológicos e comportamentais que influenciam a ocorrência de problemas de saúde e seus fatores de risco na população. A comissão homônima da Organização Mundial da Saúde (OMS) adota uma definição mais curta, segundo a qual os DSS são as condições sociais em que as pessoas vivem e trabalham?.

Apesar da preocupação de diversos autores em conceituar os DSS, denota-se sua definição como fatores de ordem social que interferem no processo saúde-doença das pessoas $\mathbf{1}$. Na perspectiva da atuação profissional, são entendidos como fatores que podem ser modificados por meio de intervenções baseadas em informações ${ }^{1}$. Ainda sobre a necessidade de intervir nesses fatores e na prática profissional na saúde pública, observa-se que:

[...] o próprio termo 'saúde pública' expressa seu caráter político e que sua prática implica necessariamente a intervenção na vida política e social para identificar e eliminar os fatores que prejudicam a saúde da população'.

É importante lembrar que o Movimento da Reforma Sanitária Brasileira responsabilizou o Estado por garantir acesso aos serviços e ações de saúde de forma igualitária, sem preconceitos ou privilégios. A equidade, entendida como a igualdade proporcional em que se "distribuem partes diferentes a pessoas diferentes, na proporção da diferença" ${ }^{2}$, visa, na prática, nivelar as desigualdades provocadas pelos DSS.

As populações de ocupações são um dos exemplos de população vulnerável, expostas a iniquidades; portanto, deveriam ser priorizadas pelos profissionais de saúde e assistência social. O Instituto Brasileiro de Geografia e Estatística (IBGE) classifica as ocupações como aglomerados subnormais, conceito criado em 1987 e aplicado em 1991. No censo de 2010, houve a maior quantidade de avanços em relação à identificação e ao levantamento de dados dos aglomerados subnormais ${ }^{3-5}$.

Um aglomerado subnormal deve ter minimamente 51 unidades habitacionais de qualquer constituição estrutural, associado normalmente à carência de serviços públicos essenciais. A população ocupa terras alheias pertencentes aos setores públicos ou privados, de forma desordenada e/ou densa ${ }^{4}$.

A classificação ocorre a partir dos seguintes critérios:

[...] a) Ocupação ilegal da terra, ou seja, construção em terrenos de propriedade alheia (pública ou particular) no momento atual ou em período recente (obtenção do título de propriedade do terreno há dez anos ou menos); e b) Possuir pelo menos uma das seguintes características: - urbanização fora dos padrões vigentes - refletido por vias de circulação estreitas e de alinhamento irregular, lotes de tamanhos e formas desiguais e construções não regularizadas por órgãos públicos; ou • precariedade de serviços públicos essenciais, tais quais energia elétrica, coleta de lixo e redes de água e esgoto 4 .

Segundo o censo de 2010, os aglomerados subnormais podem ser categorizados como: invasão, loteamento irregular ou clandestino, áreas invadidas e loteamentos irregulares e clandestinos regularizados em período recente, abarcando as comunidades informalmente chamadas de favelas, invasões, grotas, 
baixadas, comunidades, vilas, ressacas, mocambos, palafitas etc ${ }^{4,5}$.

A escolha por denominar áreas onde vivem populações vulneráveis como "ocupação" deu-se em virtude do seu uso crescente pelos movimentos sociais que "[...] lutam pela moradia rejeitam o termo 'invasão', que consideram ofensivo e adotam 'ocupação"'6, em substituição ao significado negativo que o termo ‘invasão' geralmente carrega.

O termo invasão remete a um invasor, aquele que deve ser retirado do espaço que não é seu, ficando sem endereço, e, mesmo quando consegue se estabilizar em um local, o Estado não o reconhece como seu, não é seu endereço oficial, o que corresponderia à ilegalidade. Essa realidade traz repercussões sociais, como sensação de provisoriedade ou invisibilidade social.

Socialmente a invisibilidade acarreta um vasto conjunto de formas de exclusão e/ ou discriminação por vezes escamoteadas que gravitam em torno de produção de percepções,'equivocadas e interessadas' que objetivam conduzir a negativas de reconhecimento da diferença cultural. Trata-se da produção de imaginários que idealizam e celebram determinadas formas de ser percebidos e enraizados através de aprendizados partilhados, que rejeitam a dinâmica cultural e produzem assimetrias equivalentes a um não existir como correlato?.
Alguns dos DSS estão fortemente presentes nessas populações, inicialmente classificadas pelo IBGE como as que têm carência de serviços públicos essenciais. Sua vulnerabilidade corresponde a retrocessos nas garantias de direitos como

[...] acesso à moradia, serviços de saúde, assistência social e emprego, coexistência de modalidades arcaicas e modernas de trabaIho, com importante participação da informalidade não legalmente protegida(180).

\section{Metodologia}

Pesquisa qualitativa que objetivou identificar quais DSS estão presentes na realidade de uma população de ocupação de Campinas, no ano de 2019, com ênfase em acesso a serviços de saúde, habitação e trabalho, identificados a partir de entrevistas semiestruturados com 10 moradores da referida ocupação, conforme amostra por conveniência, a partir de roteiro elaborado com essa finalidade. Utilizaram-se dados secundários presentes no Censo Demográfico Comunitário 9 , elaborado e aplicado pela liderança comunitária da população no ano de 2018 para descrição e caracterização do perfil sociodemográfico da população estudada, por meio das seguintes variáveis: sexo, idade, total de famílias e moradores brasileiros e estrangeiros. 
Gráfico 1. Número de moradores por faixa etária discriminado por sexo

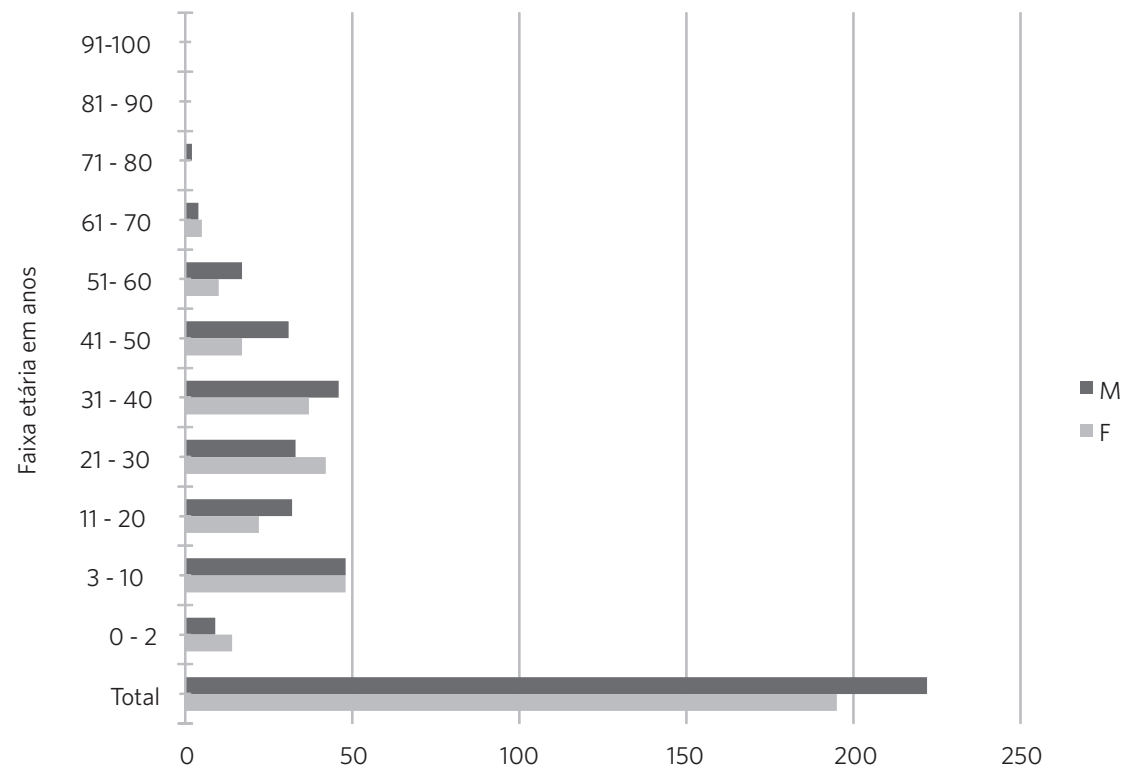

Fonte: Censo Demográfico Comunitário ${ }^{9}$.

Os participantes da pesquisa foram escolhidos mediante os seguintes critérios: ser ou ter sido morador da comunidade e idade igual ou superior a 18 anos.

A pesquisa foi aprovada pelo Comitê de Ética em Pesquisa, sob parecer de $\mathrm{n}^{\mathrm{o}}$ 3.146.364.

Os resultados foram interpretados e analisados segundo técnica da análise de conteúdo ${ }^{10,11}$, após identificação das seguintes categorias analíticas: caracterização dos entrevistados; história da ocupação e o viver no território; DSS, com as seguintes subcategorias: condições de vida e saúde na ocupação; abastecimento de água, saneamento básico e saúde; estrutura da moradia e saúde; desemprego, renda e saúde; acesso a serviços de saúde. Agregou-se a subcategoria violência e saúde, pois foi tema que emergiu das entrevistas e não constava do roteiro original.

\section{Resultados e discussão}

\section{Caracterização do perfil sociodemo- gráfico segundo censo demográfico comunitário}

O Censo Demográfico Comunitário dá continuidade ao cadastro inicial de pessoas residentes na ocupação, elaborado pelo coordenador dela, com o intuito de gerir a entrada, a permanência e a saúda de famílias, a fim de otimizar e controlar o uso do território, construção de barracos, fossas e acesso à água. Existe a preocupação de mantê-lo atualizado. De acordo com esse censo, há 421 moradores, correspondendo a 141 famílias e domicílios, o que caracteriza o território como aglomerado subnormal ${ }^{3}$. Do total de moradores, 346 (82,18\%) são brasileiros; e $75(17,81 \%)$, imigrantes, em sua maioria 
haitianos, correspondente a 22 famílias. A média de moradores por domicílio é de 2,99.

Em relação ao sexo, o número de homens corresponde a 222 (53,23\%); e de mulheres, a 195 (46,76\%). Em relação à faixa etária, há predomínio dos indivíduos de 3 anos a 10 anos (22,30\%), para ambos os sexos. O menor número de indivíduos está entre 71 anos e 80 anos (0,24\%). Trata-se de uma população composta predominantemente por crianças, adolescentes e adultos jovens, sendo apenas 11 indivíduos com 60 anos ou mais (2,64\%), o que destoa claramente do cenário nacional que apresenta mais de $13 \%$ de idosos e com previsão de aumento acelerado da porcentagem de idosos.

\section{Caracterização dos entrevistados}

Entrevistaram-se 8 mulheres e 2 homens, cujas idades variaram entre 18 anos e 60 anos. O tempo médio de residência na ocupação foi de 2,71 anos, com 6 pessoas morando há mais de três.

Seis pessoas recebem algum tipo de benefício social: cinco são bonificados com o programa Bolsa Família e um recebe o Benefício de Prestação Continuada (BPC). Os demais entrevistados não recebem benefício social. Quanto ao número de filhos por família, obteve-se média de 2,6, sendo o perfil etário semelhante ao perfil sociodemográfico da população total da ocupação. Quanto ao total de pessoas por família, a média foi um pouco mais elevada do que a média da população, variando do mínimo de 1 ao máximo de 7 pessoas.

Sobre a nacionalidade, 9 são brasileiros; e 1 mulher é haitiana.

\section{História da ocupação e o viver nesse território}

A ocupação do espaço ocorreu no dia 15 de agosto de 2015. Foram erguidos barracos de madeira forradas com lona. A área ocupada pertencia à Secretaria Municipal de Educação.

No quarto dia de ocupação, houve uma tentativa de reintegração de posse por parte do Poder Público Municipal, em que estavam presentes máquinas, funcionários municipais e policiamento. Tal reintegração não foi bem-sucedida devido à falta de um documento oficial. A partir desse dia, formou-se uma comissão organizadora da ocupação que existe até os dias atuais, mediando a comunicação entre os moradores, a Companhia de Habitação Popular de Campinas e a Prefeitura Municipal.

[...] E eu já não estava trabalhando, estava desempregada na época... e assim, a gente ficava aqui... aí ninguém pode sair, quem quiser fica aqui, não pode dormir fora. Meu pai fez uma estrutura assim, com madeira, tipo um triângulo na época, e a gente passou uma lona naquilo, só que ela movia, né. [...] Três horas da manhã passavam com um sino, tinha que subir pra responder, era uma loucura! Era uma loucura! E10.

Ao perguntar o motivo de estarem morando na ocupação, dois dos entrevistados deixaram a casa de alvenaria onde viviam por estarem saindo de um relacionamento conflituoso, alegando não ter outra opção para não ficar na rua. Outros dois entrevistados gostariam de assegurar uma casa para seus filhos. No caso da família imigrante, vieram para o Brasil devido ao falecimento do pai, que veio anteriormente ao Brasil em busca de emprego e já vivia na ocupação. Outros três entrevistados apontam o desemprego como motivo. Outro fator foi a dificuldade em pagar aluguel ou adquirir imóvel, evidenciando a renda como um fator de vulnerabilidade social. Pasternak ${ }^{4}$ afirma que, no Brasil, "o preço elevado da terra e da moradia faz com que a alternativa da ocupação seja uma das poucas possíveis para a grande parte da população brasileira”.

Em relação aos sentimentos e sensações relatadas sobre viver naquele local, pode-se analisar aspectos positivos ou negativos. Os negativos dizem respeito a ser um local ruim para morar por questão de saúde, sofrimento devido à queima de 
objetos, dor relacionada com a perda de uma realidade anterior de uma moradia digna; estranheza por necessitar se adaptar ao local (a imigrante); medo de perder suas coisas durante um incêndio; tristeza causada por instabilidade; discriminação social pela situação de 'favelamento', sentimento associado à pobreza:

Ah, vamos supor, cê vai, tem loja ali no CDHU, você vai lá no CDHU numa loja. Se vai entrar lá dentro, a turma olha o seu pé, ol ha como que está a cor. É favelado, é da favela. Centro de Saúde também, já teve discriminação, entendeu? Porque as pessoas olham, olham pra você diferente, por você morar aqui. E4.

Segundo a Oxfam Brasil12, a sociedade divide as pessoas em categorias que definem quem deve ter seus direitos básicos respeitados ou negados, tornando normais as desigualdades sociais presentes no cotidiano em "um país onde morar em periferias ou ser negro e negra já define, de antemão, a qual categoria você pertence", o que traduz de alguma forma a fala da entrevistada.

Em relação aos aspectos positivos, destacam-se os sentimentos de privacidade, liberdade, independência, sonho de ter casa para abrigar os filhos, sentir-se 'viva'; gratidão por ter onde morar; alegria por conhecer e se sentir ajudada pelas pessoas da ocupação.

E é graças a ele que meu filho tem uma vida saudável, meus filhos têm, né... Hoje eu consigo dar para os meus filhos uma vida, apesar de que o lugar não é lá dos melhores, mas é um lugar onde eu me sinto viva [...]. E3.

Concluiu-se que houve maior associação entre viver na ocupação e dificuldades, e o reconhecimento da importância do direito à moradia para o bem-estar humano, conforme a Constituição Brasileira de $1988^{13}$ defende, colocando a moradia como um direito e garantia fundamental ao ser humano.

\section{Determinantes Sociais da Saúde}

\section{CONDIC̣ÕES DE VIDA E SAÚDE NA OCUPAC̣ÃO}

No entendimento dos moradores da ocupação sobre os fatores que pioram ou melhoram suas condições de saúde, foram mais significativos os seguintes: agravamento de sintomas respiratórios relacionado a pó e cheiro de mofo; condições de saneamento básico (falta de água encanada, fossa rudimentar, sem recolhimento de esgoto, acúmulo de lixo e materiais reciclados); presença de animais, como ratos, e outros vetores de doenças; e violência. Dois dos entrevistados identificaram melhora da sua condição de vida e saúde, relatando melhora de estado mental e físico por ter uma moradia, espaço seguro para que os filhos tenham sua infância, e o outro relaciona a ter acesso a atendimento na Unidade Básica de Saúde (UBS). Três dos entrevistados não identificaram tais fatores, relacionando-os com piora ou melhora de suas condições. Por outro lado, a maioria dos entrevistados associa o fato de morar na ocupação a alguma piora na sua saúde:

[...] Mas esses dias, que nem agora que está chovendo direto, eu percebo que ela fica roncando, fica muito catarro... no peito. Então ela ronca, ela sente dificuldade pra dormir. Acho que até mesmo o cheiro disso aqui, né, ataca. [...] Que a médica já me perguntou pra mim, se eu não tenho condição de sair daqui. Eu não tenho, não tenho pra onde ir [...] Vou ficar aqui mesmo. Mas eu me preocupo muito com essa asma dela, com esse problema dela. Acho que ela fica muito vulnerável, muita, muita. De ver o que ela passou tudo, né, foi muito difícil pra mim, muito! E1.

Os DSS de enfoque da pesquisa foram então identificados pela população da ocupação como determinantes de sua condição de saúde física e mental, como iniquidades, isto é, "desigualdades de saúde entre grupos populacionais que, além de sistemáticas e relevantes, são também evitáveis, injustas e 
desnecessárias”"1 e que devem ser alteradas por intervenções.

\section{ABASTECIMENTO DE ÁGUA, SANEAMENTO BÁSICO E SAÚDE}

Na ocupação, existem 18 torneiras disponíveis para a população, trazidas do encanamento da rua por meio de caixas suspensas por bases de madeira. Essa água 'coletiva' chega às casas através de mangueiras que abastecem caixas d'água individualizadas ou por meio de baldes ou bacias. Alguns entrevistados reconhecem as condições de abastecimento e/ou armazenamento de água como algo que influencia sua saúde negativamente, seja por entender que a água pode ser contaminada por estar armazenada na caixa d'água, com risco de ter sujidade e outros contaminantes, seja por ser manuseada ou transportada em baldes, garrafas e mangueiras, causando episódios de vômito e diarreia, além de conflitos entre a população no momento de abastecimento por mangueira.

Não há tratamento de esgoto, e o escoamento se dá por valas que passam por áreas de lazer e de circulação dos moradores, com risco de contaminação do córrego que passa ao lado da ocupação, do solo, lençóis freáticos e das pessoas que transitam no local. Todas as casas possuem fossas rudimentares, sem qualquer tipo de tratamento. A coleta de lixo é considerada insuficiente, sendo visível seu acúmulo nas vielas e lugares públicos da ocupação. Os entrevistados consideram que tais condições de saneamento colocam em risco a saúde, principalmente por causa da contaminação do ambiente e das pessoas, além do desconforto pelo mau cheiro, presença de animais e insetos e perigo de queda nessas fossas:

Então quando eu ia lavar roupa... lá na bica, ia todo mundo pra bica, agora não, a maioria tem uma pia em casa, pra lavar em casa. Mesmo que não tenha, a torneira, mas tem a bacia e lava na bacia. Porque melhor do que ficar lá na bica, né. Porque juntava um monte, era fila, a gente esperava horas e horas pra poder lavar louça, pra poder lavar roupa [...] Dava briga, e era complicado, porque a gente que tem criança, não podia deixar de levar, bebezinho. Foi muito sofrido, muito sofrido. E1.

[...] a mangueira ela não tá tendo manutenção, querendo ou não, ela é uma mangueira de jardim, ela junta um lodo. Então querendo ou não eu acho que a falta d'água encanada aqui, abala sim, porque tem pessoas que ficam com virose, né. Tem época aqui que todo mundo tava com diarreia, vômito, por conta acho que da água mesmo. Você sabe que a água ela é o bem maior que a gente precisa, porém ela pode também tornar um veneno pra gente, pra saúde. E a água eu acho que faz muita falta, a água canalizada. E3.

E sobre o esgoto:

[...] querendo ou não, a gente tem fossa. Fossa dentro de casa ela vai [...] atrair ratos, barata. Vai atrair, querendo ou não pode atrair até escorpião. Porque fica um local úmido e sempre, querendo ou não, a maioria das pessoas cobrem com palete, né. Então querendo ou não acho tem sim esse dano por conta de rato, é o esgoto, barata. E3.

Comparando-se essas informações com outros estudos da região Sudeste, verifica-se que apenas " $4,24 \%$ das casas têm fossa rudimentar, 6,65\% jogam dejetos em valas e $11 \%$ o fazem em rios, lagos ou direto no mar". Como afirma Pasternak ${ }^{5}$, apesar dos indicadores dessa região do Brasil serem melhores do que outras regiões do País, na ocupação estudada, $100 \%$ dos moradores não têm acesso, ou acesso muito restrito à água encanada, esgotamento sanitário, coleta de lixo regular. O mesmo autor apresenta dados para a região Sudeste de 20,18\% de domicílios com coleta de lixo por meio de caçambas, o que na ocupação também corresponde a $100 \%$ dos domicílios, o que favorece claramente a presença de animais, insetos vetores e outras pragas urbanas, trazendo risco à saúde e doenças decorrentes dessa exposição 5 . 


\section{ESTRUTURA DA MORADIA E SAÚDE}

Todas as moradias são feitas de madeira, algumas têm o piso cimentado ou forrado com tapete. Quatro dos entrevistados não identificam problemas de saúde relacionados com a estrutura da casa. Os demais identificam o cheiro de mofo, dificuldade para higienizar a casa, falta de conforto, desconforto térmico no interior da residência, infiltração, poeira ou lama constante, além da entrada de animais como condições para piora da saúde.

Chove mais dentro do que fora [...] é ruim, o mau cheiro, é madeira [...] se chove muito e tal, dá o cheiro de mofo. Entendeu? O cheiro de, coisa ruim. E se tá calor você não aguenta viver dentro de casa. O chão também, que não é, é na terra! A gente coloca uns carpete, coloca uns carpete, não tem piso aí é o carpete. Aí tudo ali vai juntar fungos, vai juntar tudo! [...] eu tenho rinite, alérgica! Entendeu? Tem dia que eu não respiro! E4.

Ele, eles fica aqui em casa, mas eu tenho que dar o antialérgico. $\mathrm{O}$ meu outro filho, veio um final de semana [...] ele 'empolou' tudo... o olho dele ficou pequininho [...] só dele entrar ali dentro do quarto ali ó [...] Então também isso me prejudica, porque eles não querem vir [... n nossa eles ficam bravo, eles não gostam [...] Aí eu cimentei o quarto deles pra ver se melhorava, né. Não melhorou! E1.

Outra percepção apresentada por essa moradora tem relação com a aglomeração de pessoas na ocupação e a vivência mais próxima com pessoas em situação de uso abusivo de álcool e outras drogas:

porque aqui é, as coisa é muito concentradas [...] Se é confusão, é muito concentrada. Se é vício, é muito concentrado. Cê entendeu? Porque [...] quando a gente tá assim no bairro [...] a gente vê tudo bem, mas parece que não é tanto como aqui. Aqui afeta a gente. Afeta! [...] Porque é muita, muita gente, é aglomeração, entendeu? Fazendo a mesma coisa. É muita gente. No começo [...] era só bêbado [...] só bêbado, que você via debaixo da árvore [...] E, quando usa droga, é muito, junta muito [...] Junta aquela roda pra fumar maconha. Então tipo assim, pra gente que tem criança a gente fica também incomodada. E1.

O espaço pode ser um importante fator para compreender a condição de vida dessas famílias, obrigadas a conviver com situações e piora da saúde física e mental, compelidas a viver em espaços individuais e coletivos muito limitados.

O aumento de domicílios favelados observado nos últimos anos está recriando favelas precárias de madeira 5 . Analisar a condição de moradia nessa ocupação, em 2019, parece confirmar esse fenômeno já observado no último censo de 2010 .

A maior parte dos entrevistados identificam problemas relacionados com a estrutura de sua moradia como responsáveis por afetar sua saúde e a de seus filhos. No entanto, a falta de outras de opções, a limitação econômica e a falta de emprego não lhes permitem mudar de local; e a exigência legal de serem as moradias de madeira, e não de alvenaria, os obriga a se manterem nessa condição.

\section{DESEMPREGO, RENDA E SAÚDE}

Apenas uma das entrevistadas não considerou desemprego e renda como algo que afeta a sua saúde. Os demais associaram esses dois fatores à possibilidade de falta de comida, não poder oferecer aos filhos aquilo que pedem, origem de estresse, preocupações que podem levar a doenças físicas e mentais.

A maioria dos entrevistados está dentro da faixa de $60,6 \%$ de pessoas que atualmente não têm ocupação em Campinas ${ }^{\mathbf{1 4}}$.

Em relação à renda mensal familiar, calculada em salários mínimos (valor considerado para o País de R \$ 954,00), sete entre os entrevistados têm renda menor do que 1 salário mínimo, e três têm renda entre 1 e 2 , o que é menor do que a renda média dos trabalhadores formais $-3,8$ salários mínimos - em Campinas ${ }^{\mathbf{1 4}}$.

Para facilitar a compreensão do que a renda representa para os entrevistados, foi construída 
uma classificação, para a qual foram obtidas as seguintes respostas: $60 \%$ dos entrevistados classificam a sua renda como 'falta pouco para atingir suas necessidades pessoais e de sua família', e $40 \%$ deles a classificaram como 'falta muito para atingir suas necessidades pessoais e de sua família'. Nenhum dos entrevistados considerou sua renda suficiente ou na conta certa para o básico ou para poupar o mínimo para necessidades extraordinárias.

Trabalho e renda são fatores que podem determinar as condições de saúde e doença dessas pessoas, inseridas no percentual de $30,2 \%$ da população de Campinas com rendimento nominal mensal per capita correspondente a até meio salário mínimo ${ }^{\mathbf{1 4}}$. Este dado é ainda mais preocupante se considerarmos que a cidade de Campinas está na posição 292 em relação ao Produto Interno Bruto (PIB) per capita do País e que o Índice de Desenvolvimento Humano (IDHM) da região metropolitana de Campinas é alto ${ }^{15}$. O Mapa de IDHM da Região Metropolitana de Campinas revela que os recursos e a renda são mal distribuídos, o que reflete as desigualdades sociais expressas em valores como $10,9 \%$ de pessoas vulneráveis à pobreza e $2,74 \% \mathrm{e}$ $0,73 \%$ de pessoas classificadas como pobres e extremamente pobres ${ }^{15}$.

Segundo Buss e Pellegrini Filho ${ }^{16}$, "o fator mais importante para explicar a situação sanitária geral de um país não é sua riqueza total, mas a maneira como ela se distribui”. Em Campinas, persiste a existência de populações tão vulneráveis, como a da ocupação estudada, em uma cidade cujo PIB per capita e IDHM são altos para determinadas áreas; porém, a outras regiões e grupos vulneráveis, restam condições sub-humanas e indignas para viver. Ou, como afirma Marmot 17: "A injustiça social está matando em grande escala".

\section{VIOLÊNCIA E SAÚDE}

Três de dez entrevistados relataram ter vivenciado situações de violência ocorridas dentro da ocupação. A violência pode ser definida como o uso intencional da força ou do poder físico, de fato ou como ameaça, contra si mesmo, outra pessoa ou um grupo ou comunidade, que cause ou tenha muitas possibilidades de causar lesões, morte, danos psicológicos, transtornos do desenvolvimento ou privações ${ }^{18(500)}$.

Um dos casos de violência relatados pode ser enquadrado na definição de violência doméstica ${ }^{18}$, geralmente associadas a casos de feminicídio, quando ocorrem dentro do ambiente domiciliar, usualmente entre familiares e ou companheiros:

Teve [...] esses tempo, acho que foi dia sete. $\mathrm{O}$ irmão dele já estava aqui, sabe? Teve agressão, cê entendeu? Da parte dele. Teve agressão, ele me agrediu [...] E aí, tipo assim, só eu, eu que tive que me defender sabe. Eu que tive que me defender, mesmo eu gritando socorro, parece que você percebe que ninguém vem te ajudar. $O$ cara pode estar ali te matando [...] Eu que tive que lutar com ele, e me soltar dele, porque ele estava bêbado. Há quatro dias drogado, cê entendeu? E ele veio pra cima de mim [...] grudou logo foi no meu pescoço, com a mão ele segurou no meu pescoço. E1.

O Centro Latino-Americano de Estudos de Violência e Saúde Jorge Careli (Claves) também conceitua outros tipos de violência, como a estrutural, que se manifesta por meio da manutenção das desigualdades sociais; e a violência social, na qual se identifica a discriminação social de determinados grupos ${ }^{\mathbf{1 8}}$, exemplificada no seguinte relato:

[...] as vezes eu fico com síndrome do pânico, às vezes eu vejo uma viatura, eu começo, meu coração dispara, mão congela, eu começo a passar mal. Esse é o lado ruim. Porque infelizmente a nossa segurança, os policiais que eram pra estar nos protegendo, estão nos vendo como marginais, como a bandidagem e por conta da gente ser menos favorecidos, né em questão financeira. E por conta da gente morar em barraco, ser uma comunidade ocupacional, então eles vêm, 
tudo que acontece por aqui na região é a gente que paga. E querendo ou não isso me deixa mal, porque eu vejo eles apontarem a arma na cara dos meus filhos, que por várias vezes já entraram dentro da minha casa, já fizeram isso. Se você perguntar o meu filho fala! E3.

A entrevistada confirma o abuso de poder policial, que se baseia na discriminação de classe social à qual pertence. Outra questão a ser destacada é o fato de a entrevistada ser negra, e segundo dados da Oxfam Brasil12, " $81 \%$ acreditam que a cor da pele influencia a decisão de uma abordagem policial" e " $71 \%$ concordam que a justiça é mais dura com negros", denunciando o racismo estrutural que causa danos físicos e psicológicos, portanto, questões étnico-raciais também como fatores determinantes a mais para sua condição de saúde.

Essa população também está sujeita à violência estrutural, pois está submetida a condições de vida sub-humanas, originadas principalmente da desigualdade social observada no País, que deveria comprometer as políticas públicas intersetoriais no combate à violência:

A única certeza é que a erradicação da pobreza e das desigualdades sociais e econômicas deve fazer parte integral de qualquer programa de luta contra a violência18(504).

A violência também é associada à pobreza, pois, segundo Guerrero et al.18(503), "os pobres são, ao mesmo tempo, agressores e vítimas", o que se pode notar nas falas dos entrevistados, moradores da ocupação, na qual as relações estabelecidas entre as próprias crianças reproduzem a violência cotidiana a que estão expostas. Além disso, fica evidente também a violência presente entre os moradores, particularmente os representantes do 'estado paralelo', que definem suas próprias leis, o que gera um ciclo vicioso de criminalidade e pobreza.

Na contramão da tendência nacional de predomínio da população feminina que corresponde a quase $52 \%$ do total de habitantes, com uma relação de sexo (número de homens para cada 100 mulheres) de 96, na ocupação estudada, há predomínio de homens, o que faz com que a violência seja frequente, tendo em vista que esta, em geral, contribui para a afirmação identitária de homens e corresponde à expressão de uma forma de masculinidade hegemônica em nossa sociedade, e deve, portanto, receber atenção especial por parte das equipes de saúde de referência ${ }^{19}$.

A violência apareceu neste estudo como tema emergente, evidenciado em todos os relatos dos entrevistados, o que a torna um dos DSS presentes na vida desses moradores, mais suscetíveis a danos físicos e psicológicos decorrentes desse condicionante, e como uma necessidade em saúde complexa e contínua.

\section{ACESSO A SERVIC̣OS DE SAÚDE}

A ocupação, do ponto de vista geográfico, pertencia à área de abrangência de outra UBS. Porém, a dificuldade de acesso era maior devido à distância e à falta de vínculo com a equipe de saúde. A incorporação desse novo território à atual UBS foi um processo lento; durou de 8 meses a 10 meses. Um dos entrevistados afirma que, no início, os moradores não foram bem aceitos pelos profissionais. Outras pesquisas vinculadas a um Projeto de Extensão Universitária desenvolvido no território têm como objetos de estudo a questão da incorporação de uma área de alta vulnerabilidade ao território da equipe de saúde da família, além do estudo dos itinerários terapêuticos dos usuários em busca de atendimento médico. Esse projeto de extensão universitária, com dimensões ligadas ao ensino, pesquisa e extensão, do qual alguns dos autores desta pesquisa participam, tem buscado aproximar os moradores da ocupação à UBS20.

Atualmente, os entrevistados estão cadastrados e se utilizam da UBS. Ao perguntar sobre se conseguem ser atendidos quando adoecem ou de acordo com as suas necessidades em saúde, cinco entrevistados responderam positivamente, e uma delas garante ter um acesso bom e facilitado: 
[...]a gente tem um acesso muito bom com o Centro de Saúde, todo morador aqui. Meu, o centro de saúde já fez campanha aqui, já fez campanha de vacinação de porta em porta. E10.

Outros cinco entrevistados afirmam que suas necessidades não são plenamente atendidas, alegando falta de profissionais, má qualidade do atendimento, falta de vagas para atendimento médico, psicológico e de medicamentos. Mencionam ainda que o tempo de espera pelo atendimento do Serviço de Atendimento Móvel de Urgência (Samu) é longo e pouco frequente dentro da ocupação.

Com exceção da queixa sobre discriminação por ser morador da ocupação, as demais queixas sobre redução de acesso parecem estar relacionadas com problemas estruturais e com lacunas no atendimento devido à falta de profissionais, não específicas para moradores da ocupação, e, sim, para a população geral, em razão do subfinanciamento da maior política pública do País, o Sistema Único de Saúde (SUS) ${ }^{21}$.

Dois entrevistados comentam que são tratados de forma diferente e negativa, com descaso e discriminação, e outro, ao contrário, relata ser bem tratado justamente por viver na ocupação. Outro relata que no início da ocupação não foram bem aceitos pela equipe da unidade de saúde. Os demais entrevistados não referem diferença de tratamento por serem moradores da ocupação. Nenhum dos entrevistados relatou dificuldade em se cadastrar no centro de saúde por falta de documento.

\section{Considerações finais}

O conceito ampliado de saúde presente na Constituição Federal e na Lei Orgânica da Saúde traz consigo a importância dos DSS na compreensão do processo saúde-doença, para além das causas meramente ligadas aos aspectos biológicos e da relação agente-hospedeiro-ambiente, visão naturalizada e ainda hegemônica nos meios acadêmicos e da sociedade, a despeito do Movimento da Reforma
Sanitária Brasileira, cujos atores sociais que o compõem continuarem sua cruzada contra-hegemônica em reafirmar a necessidade de políticas públicas que extrapolem o setor saúde para alterar significativamente o quadro sanitário do País.

O presente estudo sobre os DSS em uma área de ocupação, de alta vulnerabilidade social, foi capaz de revelar o quanto a desigualdade no acesso a serviços básicos e a privação de direitos de cidadania, como acesso a serviços de saúde, moradia digna, saneamento básico, trabalho e renda minimamente adequados, têm impacto direto sobre a saúde das pessoas moradoras dessas ocupações. Além disso, outros fatores, como a violência, o preconceito e a discriminação de variadas naturezas, também foram evidenciados como geradores de sofrimento físico e psíquico.

Essas áreas de ocupação ou outras consideradas como 'aglomerados subnormais' têm crescido no País, como aponta o último censo realizado pelo IBGE, surgindo como fenômeno social nos grandes centros urbanos, como a 'favelização de barracos de madeira', condição muitas vezes imposta pelo próprio poder público, como forma de cercear o crescimento dessas áreas até que os governos indiquem solução definitiva à questão de moradia à essas populações. Mais um indicativo da desigualdade social, uma vez que essas regiões de alta vulnerabilidade social estão justamente cravadas no seio de regiões metropolitanas e de grandes cidades, principalmente na região Sudeste do País, nas quais os indicadores sociais e econômicos, como renda per capita e IDHM são considerados geralmente muito positivos.

Profissionais de saúde, gestores públicos, universidades e outros atores sociais, comprometidos com a necessidade de mudanças no quadro sanitário brasileiro, e defesa de direitos de cidadania, devem considerar os DSS nas suas ações voltadas a populações e comunidades mais vulneráveis.

Compete à atenção básica o olhar atento, singular e equânime para as populações vulneráveis residentes em aglomerados subnormais, 
enfatizando a necessidade de visitas ao território, às famílias, e a garantia do acesso à saúde. Nesse sentido, fazem-se necessários o preparo e a capacitação adequados das equipes que oferecem ações de saúde a essas populações. A falta de arruamento adequado, a ausência de endereço, de nome de rua e de número nas casas não devem ser impeditivos para as ações das equipes de saúde no território. Outro desafio, muito atual, para a atenção básica é a presença de imigrantes chegados há pouco tempo, e com dificuldade de se comunicar e de se integrar à comunidade, em razão de não dominar o idioma e que, culturalmente, podem conceber o processo saúde-adoecimento-cuidado de forma singular e diferente.

\section{Referências}

1. Buss PM, Pellegrini Filho A. A Saúde e seus Determinantes Sociais. Physis. Rio de Janeiro. 2007 [acesso em 2020 fev 16]; 17(1):77-93. Disponível em: http:// www.scielo.br/pdf/physis/v17nl/v17nla06.pdf.

2. Escorel S. Dicionário Educação do profissional de saúde da Fiocruz: Eqüidade em saúde. [internet] c2009. [acesso em 2018 abr 22]. Disponível em: http://www. sites.epsjv.fiocruz.br/dicionario/verbetes/equsau. html.

\section{Colaboradores}

Castelaneli IKM (0000-0003-3366-3102)* contribuiu para a concepção e elaboração do projeto de pesquisa, coleta de dados, análise, e elaboração do artigo. Vilela MFG (0000-0002-5894-3365)* contribuiu para a concepção e elaboração do projeto de pesquisa, análise, e elaboração e revisão do artigo. Bedrikow R (0000-0003-14053122)* contribuiu para a concepção e elaboração do projeto de pesquisa, análise, e elaboração e revisão do artigo. Santos DS (0000-0001-90603929)* contribuiu para a análise dos dados e concepção do artigo. Figueira MCS (0000-00019236-8299)* contribuiu para a análise dos dados e concepção do artigo.
*Orcid (Open Researcher and Contributor ID).
3. Instituto Brasileiro de Geografia e Estatística. Censo Demográfico 2010: Aglomerados subnormais - informações territoriais. [internet] Rio de Janeiro, 2010. [acesso em 2018 abr 22] Disponível em: https://biblioteca.ibge.gov.br/visualizacao/periodicos/552/ cd_2010_agsn_if.pdf.

4. Pasternak S, D' Ottaviano C. Favelas no Brasil e em São Paulo: avanços nas análises a partir da Leitura Territorial do Censo de 2010. Cad metrop. 2016 
[acesso em 2020 fev 16]; 18(35):5-99. Disponível em: http://www.scielo.br/pdf/cm/v18n35/2236-9996cm-18-35-0075.pdf.

5. Instituto Brasileiro de Geografia e Estatística. Aglomerados Subnormais do Censo de 2010. [internet] 2011. [acesso em 2018 abr 22]. Disponível em: https://ww2.ibge.gov.br/home/presidencia/noticias/ imprensa/ppts/000000069235121120113554156750 88.pdf.

6. Maricato E. A terra é um nó na sociedade brasileira ... também nas cidades. [internet] [São Paulo]. 1997. [acesso em 20 maio 2019]. Disponível em: http://labhab.fau.usp.br/biblioteca/textos/maricato_terranosociedadebrasileira.pdf.

7. Brum CK, Jesus SC. Mito, diversidade cultural e educação: notas sobre a invisibilidade guarani no rio grande do sul e algumas estratégias nativas de superação. In: Horizontes Antropológicos. [internet]. 2015 [acesso em 2018 abr 30]; 21(44):201-227. Disponível em: http://www.scielo.br/pdf/ha/v2ln44/0104-7183ha-21-44-0201.pdf.

8. Sevalho G. O conceito de vulnerabilidade e a educação em saúde fundamentada em Paulo Freire. [internet]. Interface. [Botucatu]. 2018 [acesso em 2019 maio 20]; 22(64):177-188.

9. Censo Demográfico Comunitário. Campinas: Liderança local da Ocupação Vila Paula; 2018. (Material não publicado).

10. Minayo MCS. O desafio do conhecimento. 3. ed. São Paulo: Hucitec; Rio de Janeiro: Abrasco, 1994.

11. Bardin L. Análise de Conteúdo. Lisboa, Portugal: Edições 70; 1977.

12. Oxfam Brasil; Datafolha. Nós e as desigualdades: percepções sobre desigualdades no Brasil. [internet] [São Paulo] 2019. [acesso em 2019 abr 30] Disponível em: https://www.oxfam.org.br/nos-e-as-desigualdades-2019.
13. Brasil. Constituição (1988). Art $6^{\circ}$. Dos direitos e garantias fundamentais. [acesso em 2019 abr 30]. Disponível em: http://www.senado.leg.br/atividade/ const/con1988/con1988_04.02.2010/art_6_.asp.

14. Instituto Brasileiro de Geografia e Estatística. Brasil/São Paulo/Campinas: Panorâma. [acesso em 2019 abr 30]. Disponível em: https://cidades.ibge.gov.br/ brasil/sp/campinas.

15. Instituto de Pesquisa Econômica Aplicada; Fundação João Pinheiro; Programa das Nações Unidas para o Desenvolvimento. Atlas do Desenvolvimento Humano nas Regiões Metropolitanas Brasileiras: Série Atlas do Desenvolvimento Humano no Brasil. [internet] Brasília, DF; 2015. [acesso em 2019 abr 30] Disponível em: http://www.ipea.gov.br/portal/images/ stories/PDFs/livros/livros/atlasdodesenvolvimentohumanorms_rm_campinas.pdf.

16. Buss PM, Pellegrini Filho A. Iniquidades em saúde no Brasil, nossa mais grave doença: comentários sobre o documento de referência e os trabalhos da Comissão Nacional sobre Determinantes Sociais de Saúde. Cad. Saúde Pública. 2006 [acesso em 2020 fev 16]; 22 (9):2005-8. Disponível em: http://www. scielo.br/scielo.php?script=sci_arttext\&pid=S0102-311X2006000900033.

17. Marmot M Sir. Health Inequities and Social Determinants of Health. In: Conferência na 19a International Conference of Integrated Care [internet]; $2 \mathrm{abr}$ 2019; San Sebastian: 2019. [acesso em 2020 fev 10]. Disponível em: https://drive.google.com/drive/fold ers/1VYV4RIIwRzfEIzDovHpRdOMjUsG2Rf-y.

18. Guerrero R, Lozano R, Espinosa R, et al. Violência e saúde: o desafio de um problema social nas Américas. In: Galvão LAC, Finkelman J, Henao S. Determinantes ambientais e sociais da saúde. Rio de Janeiro: Fiocruz; 2011. p. 497-511.

19. Schraiber LB, Barros CRS, Couto MT, et al. Homens, masculinidade e violência: estudo em serviços de atenção primária à saúde. Rev. bras. epidemiol. [internet]. 2012 [acesso em 2019 out 12]; 15(4):790-803. Disponí- 
vel em: http://www.scielo.br/scielo.php?script=sci arttext\&pid=S1415-790X2012000400011\&lng=pt.

20. Universidade de Capinas, Pró-Reitoria de Extensão e Cultura. OcupaExtensão - "Vila Paula" [Filme]. 30 Min 38 Seg. [internet]. [acesso em 2019 jun 2]. Disponível em: https://www.youtube.com/watch?v=T 9T2RM0E66k\&list=PLA4uZZ9XaFml_tt7y_NwzOMUk5aT_Jh7a.

21. Brasil. Constituição (1988). Emenda Constitucional No 95. 15 de Dez de 2016. Altera o Ato das Dispo- sições Constitucionais Transitórias, para instituir o Novo Regime Fiscal, e dá outras providências [internet]. [acesso em 2019 abr 30]. Disponível em: http:// www.planalto.gov.br/ccivil_03/constituicao/emendas/emc/emc95.htm.

Recebido em 09/06/2019

Aprovado em 15/10/2019

Conflito de interesses: inexistente

Suporte financeiro: não houve 